Chris Sherwell on Professor Geoffrey Allen

\title{
SRC's new head, old hand
}

Geoffrey Allen heads a 400 -strong organisation that wields a budget of over $£ 125$ million and influences the fate of the great majority of Britain's basic researchers. $\mathrm{He}$ is not new to its workings. But he is new to his post. $\mathrm{He}$ took over from Sir Sam Edwards as chairman of the Science Research Council at the beginning of the month.

The job demands practical experience of research and of administration and, if possible, of the 'real world' outside both. It also demands more than a little political nous. An erratic economy makes consistent support for Britain's research effort hard to achieve. To fight for money on behalf of scientists at large, and then dispense it on behalf of the community at large, is just as difficult.

So how did Professor Allen come to it? Under the British system which chooses to recruit through the grapevine, he wasn't the first man approached. But he is realistic about this. $\mathrm{He}$ accepts the system and says he has used it himself. Equally, he'd be happy if jobs like his were advertised-provided the minister concerned (at Education and Science) was not constrained by the list of applicants. $\mathrm{He}$ is also sure that if the job had been advertised, he wouldn't have applied for it.

$\mathrm{He}$ is admirably qualified, of course: a polymer scientist of 48 elected last year to the Royal Society, he has SRC and industry (especially ICI) connections going back many years. The problem was that he had recently taken up the chair of chemical technology at Imperial College, and was starting a research group there; he couldn't easily ask for a 4-year leave of absence. When the approach came, however, the decision wasn't difficult for him personally; rather, it was simply a matter of working out the possibilities and reaching agreement with Sir Brian Flowers at Imperial and with the Department of Education and Science.

What Allen calls his pragmatic view of life and work comes, he says, from his background. He was born in the Derby mining town of Clay Cross, the son of an engine driver. A Methodist Sunday School teacher taught him self-discipline. And a donnish ex-Cambridge maths teacher at grammar school inspired his love for science. He sees nothing significant in the fact that he has since 'made good". "The good thing about science", he says, "is that it doesn't signify where you come from. It's what you do that matters".

Having graduated in chemistry at Leeds and completed a doctorate there on the thermodynamics of solu- $\frac{\tilde{s}}{\mathrm{~s}}$ tions, he took the advice of Fred Dainton, now head of the University Grants Committee (UGC), and went to Canada in 1952 to learn about spectroscopy. He wanted an academic job when he returned two years later, but the pickings were thin. Geoffrey Gee, who had just left the Rubber Producers' Research Association to take up a chair in chemistry at Manchester, offered him a job "provided you work in my field and bring the techniques you've learned to bear on my problems". Allen stayed for twenty years.

Gee taught him three things: that it was possible to do good physical science on polymers; that good science is always the basis of good technology ("That coloured the whole of my career... I never had the hang-up some of my contemporaries had that there was something nasty about industry"); and that "scientists have to think more widely than just being a scientist" - a view reinforced by contact in Manchester with Brian Flowers and Sam Edwards, his SRC predecessors.

Allen acquired his experience of administration and industry during the 1960 s, sitting on government and SRC committees and consulting for companies. Then, in 1969 , in a development he sees as a crossroads, Allen helped set up the ICl/Manchester Unit Joint Laboratory he directed at Manchester. He insisted from the start that the laboratory be closed after five years, on the grounds that any worthwhile work could at least be run down steadily, any dynamic work would be picked up by ICI or the university, and any decision to re-start it could take account of experience. A little later he went half-time to the ICI corporate laboratory, also for five years.

Before Allen came to the SRC he declared all his consultancies, but served notice that he might wish to take up two while in office; this was agreed. "It would be nice to do some consulting as a working scientist", he says, "and I could do this without compromising my position". For the curious, he says his income is likely

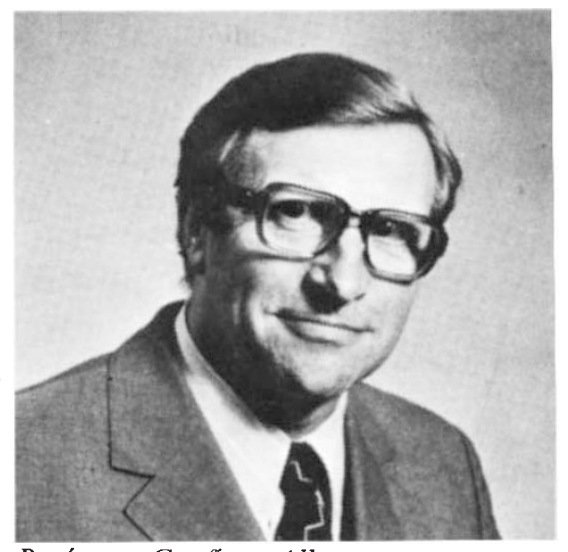

Professor Geoffrey Allen

to stay roughly the same at the SRC, with a "chance there could be a drop".

As for the coming four years, he knows the problems awaiting him. Support for high energy physics and space, for example, can't go any lower. "They're at the margin", he says. After a declining curve in the overall budget, he now wants a flat one; an inclining one, he acknowledges, would be too much to expect. But it will probably have to come out of a larger Science Budget, that is, economic growth. Among the arguments at his disposal for a greater share of that budget, however, is one that must appeal to the scientists who dispose of it: that applications for money clearly deserving support are being turned down.

Allen here distinguishes a lack of money from a surfeit of ideas. But both are problems, even if the former is sad and the latter a sign of health. He also says that the 'dual support' system for university research is not working, save in specific cases-as when the UGC had some money for new projects and could be persuaded to put it into the Interactive Computing project for British universities.

Allen also knows the standards he needs to follow. He says he'll be running "an open office", like Flowers and Edwards before him. He is conscious of a need for proper and responsible dealings with pressure groups, though he doesn't name names. He likes tackling problems, "provided they're amenable to logic", and, he says, "I can be persuaded to change my mind. Administrators must be able to do that".

He hopes to leave his successor with an operation looking as good as the one Edwards has left him. And like Edwards, he hopes to return to science, his first love. He still works at it, after all. Last year he got a grant from the SRC. 